\title{
PROCESS MODELING OF CARBON-EPOXY COMPOSITES: RESIDUAL STRESS DEVELOPMENT DURING CURE AND ANALYSIS OF FREE EDGE EFFECTS
}

\author{
Darya BONDARCHUK , Boris FEDULOV \\ Department of Aircraft Engineering, Laboratory of Composite Materials, Moscow Aviation Institute, \\ National Research University, Moscow, Russian Federation
}

Received 13 August 2018; accepted 15 March 2019

\begin{abstract}
Last decades, increased attention is paid to the deep understanding of the process induced residual stresses (locked-in) and their effect on shape distortion and fracture. Residual stresses evaluation is particularly important in multilayered composites with anisotropic thermo-mechanical properties, where the ply orientations and stacking sequences highly influence the appearing of manufacturing stresses.

In the present study, the effect of free edge on residual stresses inherited during manufacturing of thermoset multilayered composites was investigated. In order to understand the stress-strain state in samples after free edge cut a simplified 2D plane strain finite element analysis was performed. Many phenomena, such as sensitivity of the results to the size of the numerical grid, stress redistribution and size of the area affected by free edge was analyzed.

In the current research, the behavior of AS4/8552-1 carbon-epoxy composite during manufacturing cycle was studied by means of finite element modeling in ABAQUS. To describe the behavior of the composite material during the manufacturing process - including processes of formation, polymerization, development of residual strains and stresses was done by developed user subroutine-UMAT, describing the visco-elastic material behavior of the material. The program was implemented in ABAQUS and validated on the basis of literature data.

The results of the study can be applied for prediction of residual stresses in composite structure by means of virtual simulation and further understanding the nature of fracture of composites.
\end{abstract}

Keywords: residual stress, composite, free edge.

\section{Introduction}

A well-known stress concentration problem - the socalled free-edge effect was investigated by a large number of scientists (Mittelstedt \& Becker, 2007; Rasuo \& Dinulovic, 2011; Hu, Karpur, Matikas, Shaw, \& Pagano, 1995; Solis, Sánchez-Sáez, \& Barbero, 2018; Amrutharaj, Lam, \& Cotterell, 1996; Islam \& Prabhakar, 2017; Hajikazemi \& Van Paepegem, 2018). Mainly explained by the mismatch of the elastic material properties between two adjacent dissimilar laminate layers, the free-edge effect is characterized by the concentrated occurrence of three dimensional and singular stress fields at the free edges in the interfaces between two layers of composite laminates. In Shoufeng Hu et al. (1995) carried out a detailed study of the free edge effect on redistribution of residual stresses, radial residual stress reversal and interfacial debonding through theoretical modeling, numerical analysis and experimental investigation for metal matrix composites (MMCs). The consideration of the effect of internal in the study of phenomena on free edge in carbon-epoxy composites unlike MMCs is not sufficiently studied and covered in articles up to date. However, the articles devoted to the analysis of the defects in the free edge zone under loading (including thermo-mechanical loading) annually appear in scientific journals (Solis et al., 2018; Amrutharaj et al., 1996; Islam \& Prabhakar, 2017; Hajikazemi \& Van Paepegem, 2018). What is an important, in most researches, residual stress in composites are not taken into account in mathematical models.

Residual stresses can reach values close to the ultimate strength of the matrix. The existence of residual stresses combined with mechanical loads can cause several defects in composite laminates and structures such as fiber and tow misalignment, transverse cracking (known as microcracking) delamination and warpage. In particular, for

*Corresponding author. E-mail: bondarchuk.da@mail.ru 
aviation structures, the residual stresses can be unlikely ignored and should be taken into consideration during the process of design and production in view of the high cost and high reliability requirements.

Attempts of researches to investigate the thermochemical and mechanical aspects of the manufacturing processes, such as RTM, autoclave, vacuum infusion, pultrusion, were systematized and presented in (Solis et al., 2018; Amrutharaj et al., 1996; Chachad, Roux, Vaughan, \& Arafat, 1995; Islam \& Prabhakar, 2017; Hajikazemi \& Van Paepegem, 2018; Baran, Cinar, Ersoy, Akkerman, \& Hattel, 2017; Johnston, 1997; Johnston, Vaziri, \& Poursartip, 2001).

The problem of residual stress formation is complex as it depends on many factors and includes several subproblems. That is why in terms of simplicity and as the first step of research the analysis of sample with $\left[0^{\circ} / 90^{\circ}\right]_{n}$ lay-up is presented. Since there is symmetry and specimen size in third direction is supposed to be long enough, the modeling for $\left[0^{\circ} / 90^{\circ}\right]_{12}$ laminate for regular section can be provided in two-dimensional plane strain formulation. It is worth to note, effects of shape distortion and fracture effects become more evident for composites with $\left[0^{\circ} / 90^{\circ}\right]_{\mathrm{n}}$ lay-up, due to maximum difference in anisotropic properties of each individual layer.

In the present work, the modeling was considered using an example of AS4/8552-1 carbon-epoxy composite in view of the availability of data in literature. The study was conducted by means of general purpose FE package ABAQUS and special constitutive material model that was implemented in user subroutine-UMAT. The uniqueness of the current work lies in accounting residual stresses that form in composite during manufacturing when analyzing the free edge effects in the composite after cut. Note also, that analysis was provided using continuum elements which in turn made it possible to notice the effects occurring on the free edge. The developed technique will allow evaluating free edge effects for composites with arbitrary lay-up, geometry and shape of the notch.

\section{Constitutive material model}

One of the key processes during manufacturing of composite part and at the same time a bottleneck is a polymerization of resin that takes place inside the die. Residual stresses developing during manufacturing of thermoset composites have a direct influence on the product quality (Fedulov et al., 2016; Ushakov et al., 2015) and can immediately and after some period of time cause problems with assembly process as it requires to use additional spacers to ensure close contact between parts. Main factors responsible for residual stresses and shape distortions on a high-performance composite are the following- the anisotropic thermal shrinkage that occurs during cooling from cure temperature to room temperature, chemical shrinkage during the polymerization reaction, the degree of cure gradients through the composite thickness and in- teraction between die and part. To describe the behavior of composite during manufacturing it is required to take into account polymerization kinetics of resin and micromechanics of composite.

At least, three kinds of constitutive laws- elastic, the pseudo-viscoelastic "cure hardening instantaneously linear elastic CHILE model (D. Li, X. Li, Dai, \& Xi, 2017)” and viscoelastic law, are currently used to predict curing process induced residual stress for the thermoset polymer composites. In Donga Li et al. (2017) and N. Zobeiry et al. (2016) in showed that CHILE approach and viscoelastic models are most accurate and can be reliably used for modeling.

To describe the behavior of the carbon-epoxy composite (AS4/8552-1), in particular, the behavior of resin during solidification the CHILE model (Li et al., 2017) was used in view of much more efficient numerical implementation and shorter computation time. The effective mechanical properties, as well as the thermal and chemical shrinkage strains for the composite part, are calculated using micromechanical approaches (Fedulov, Safonov, Kantor, \& Lomov, 2017) on basis of material data provided in (Hexply 8552, 2019). The cure degree rate of change depends on temperature and on the attained degree of cure and can be expressed by the kinetic Equation (1).

$$
\begin{aligned}
& \frac{d \alpha}{d t}=f(\alpha, T)= \\
& K_{0} \exp \left(-\frac{E}{R T}\right)\left(1-\alpha^{n} \frac{1}{1+\exp \left[C \alpha-\alpha_{C 0}-\alpha_{C T} T\right]} .\right.
\end{aligned}
$$

For a thermoset resin glass transaction temperature $T_{g}$ is related to the degree of cure and can be found by using DiBenedetto equation (Khoun, Centea, \& Hubert, 2010):

$$
\left.T_{g} \alpha=T_{g 0}+T_{g \infty}-T_{g 0}\right) \frac{\lambda \alpha}{1-(1-\lambda) \alpha} .
$$

where $T_{g 0}, T_{g \infty}$ - glass transition temperatures for the uncured and fully cured resin respectively, $\lambda$ - material constant determined experimentally, $\alpha$ - degree of cure, which takes values in the range $[0,1]$ (uncured and fully cured resin).

Mechanical properties of resin changes during sidification. It was considered that the Poisson's ratio of resin remains constant while Young's modulus changes depending on temperature and degree of cure. Young's modulus was calculated by using CHILE (Cure Hardening Instantaneous Linear Elastic) model (Li et al., 2017):

$$
\left.E_{m} T^{*}\right)=\left\{\begin{array}{cc}
E_{m}^{0}, & T^{*}<T_{C 1} \\
E_{m}^{0}+\frac{T^{*}-T_{C 1}}{T_{C 2}-T_{C 1}}\left(E_{m}^{\infty}-E_{m}^{0}\right), & T_{C 1} \leq T^{*} \leq T_{C 2}, \\
E_{m}^{\infty}, & T^{*}>T_{C 2}
\end{array}\right.
$$

where $T^{*}=T_{g}-T$. 
The driving equations were implemented in developed user subroutine for Abaqus FEM software. Standard ABAQUS tools were used to implement thermal conductivity equations. A user subroutine UEXPAN was used in order to define iremental expansion strains specified as functions of temperature and a field variable that represent the degree of cure. HEATVAL and USDFLD subroutines were implemented in order to provide internal heat generation in heat transfer analysis and to redefine field variables at each point of material respectively.

The block diagrams of analysis demonstrated in Figure 1, where the applied user subroutines are marked in red color. Global stiffness matrix and reaction forces are calculated and updated at each increment of analysis dur-
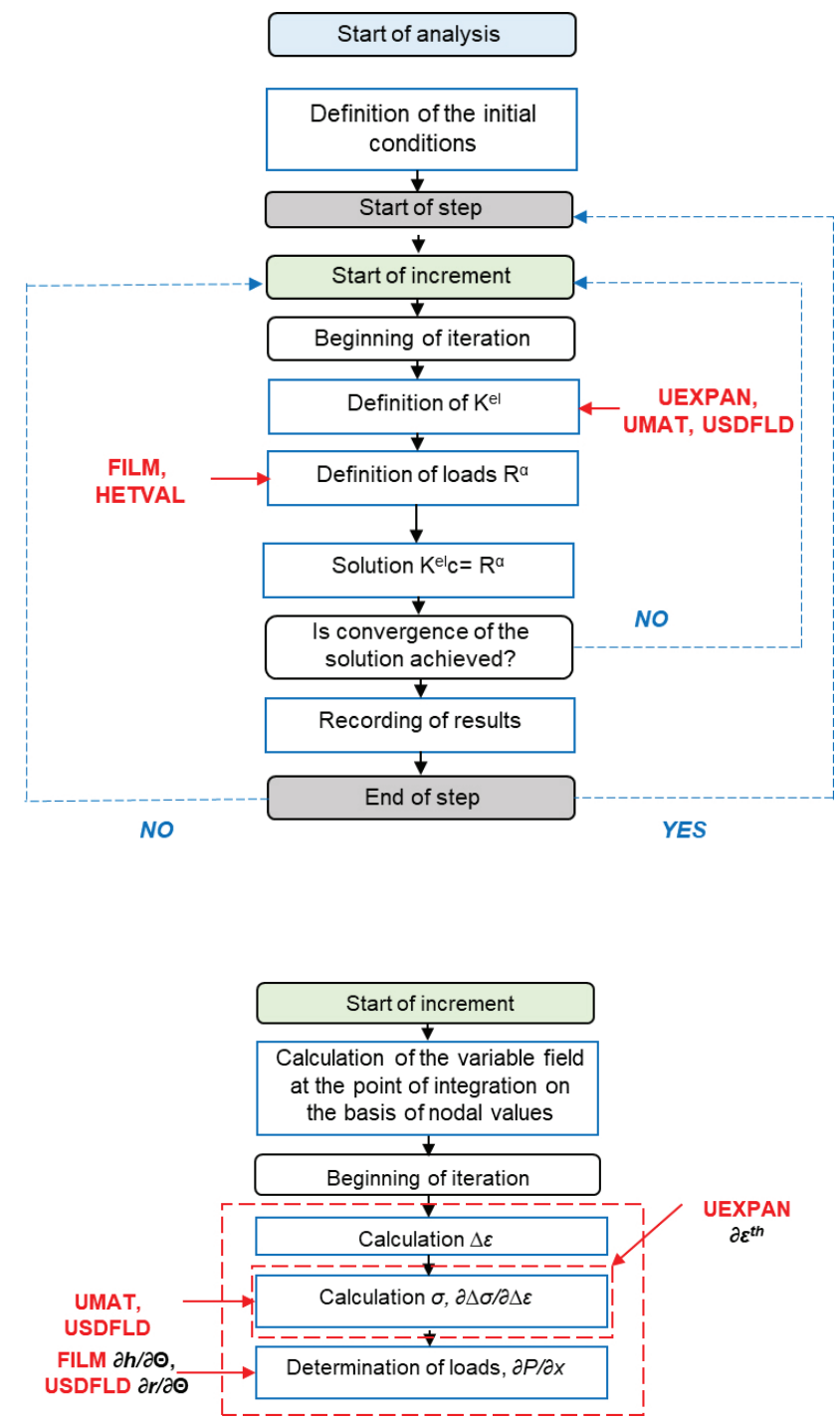

Figure 1. Global block diagram of the calculation process in the ABAQUS / Standard, showing the various available routines (in red) and the corresponding stage of the analysis and iteration in which these routines are used ing iteration. The calculation is performed for the nodal displacements. If the solution meets the convergence criteria the calculation starts for the next increment.

Figure 2 shows the development of the degree of cure, the glass transition temperature, Young's modulus and volumetric strains for resin obtained by modeling in Abaqus. The polymerization material model was verified on the example of a warping of a plate (Figure 3). Difference between the curvature of the sample obtained from the FE experiment and data provided in (Wijskamp, Akkerman, \& Lamers, 2003) is less than $3 \%$. The developed model shows the good match with literature sources (Li et al., 2017; Wijskamp et al., 2003) and can be reliably used for simulation of polymerization of the composite.
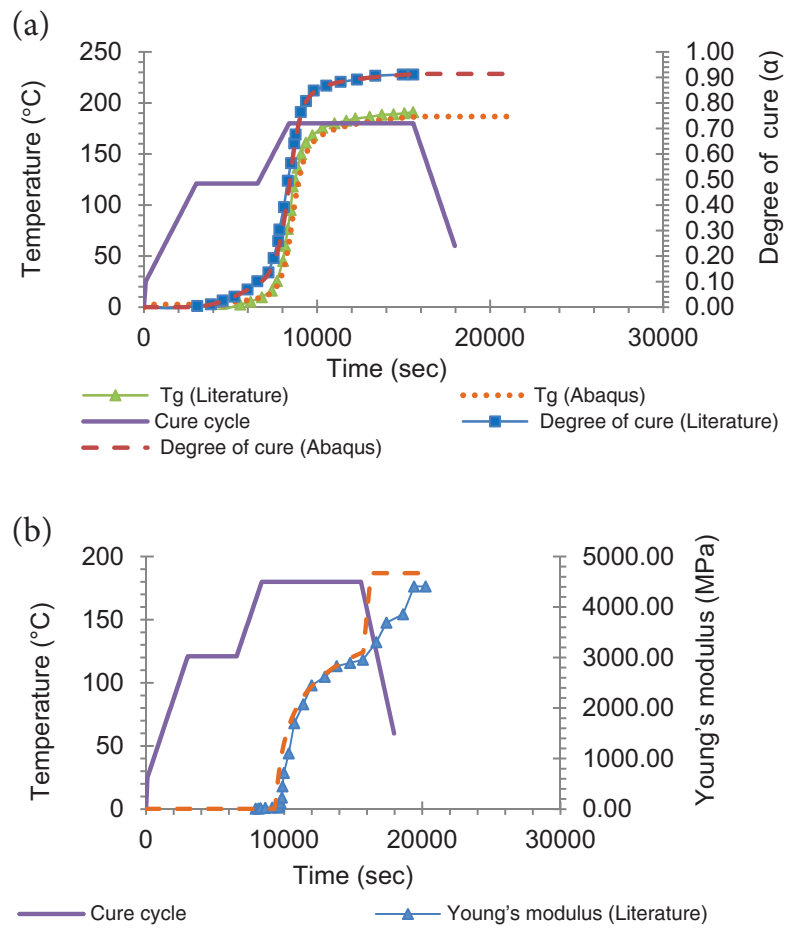

- - Young's modulus (Abaqus)

(c)

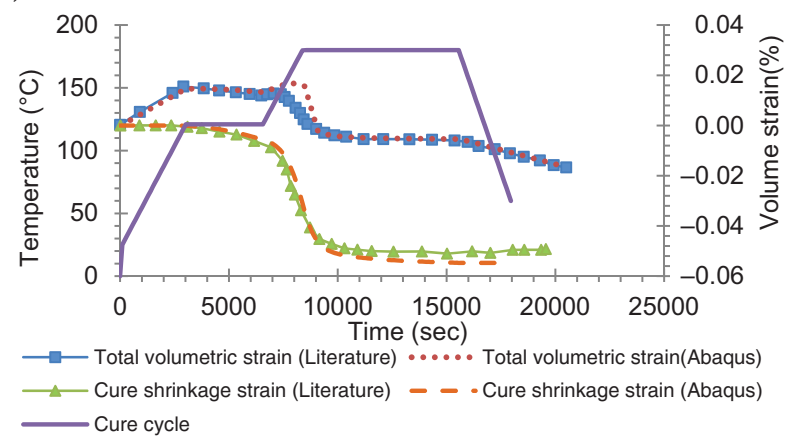

Figure 2. Development of properties of resin (a) the degree of cure and glass transition temperature (b) Young's modulus (c) volumetric strains 

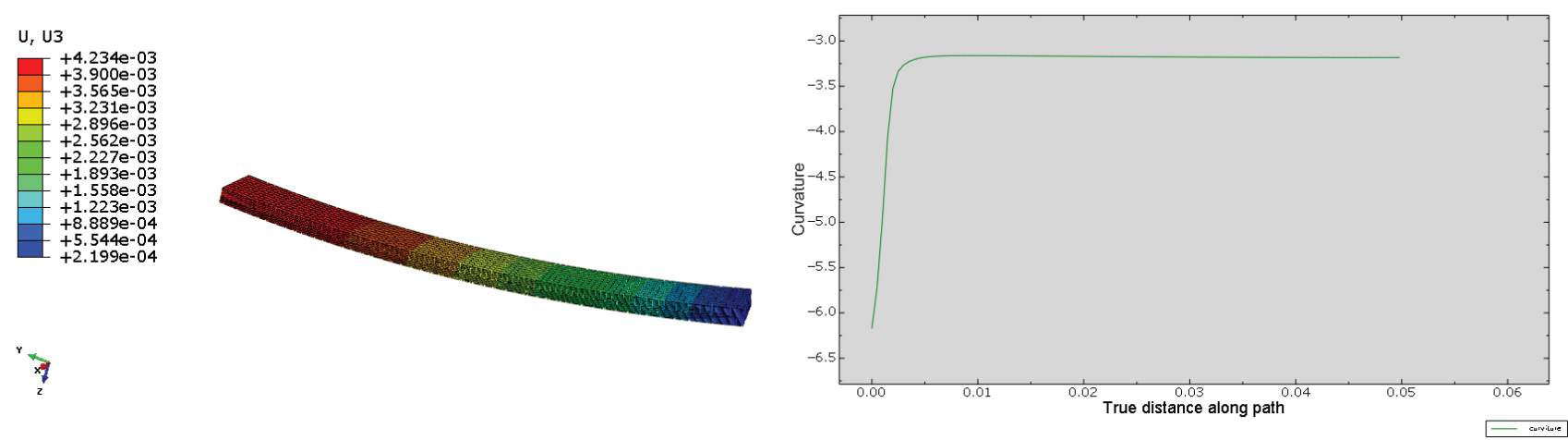

Figure 3. Verification of polymerization material model

\section{Finite element model}

In the present work, it was decided to exclude the mold from the analysis as it is insignificant for such sample. Sample considered free to move during all calculation steps. The cut process was realized by special modeling technique by deactivating interaction between two parts after cure cycle simulation using an additional step of the analysis. The coupled temperature-analysis was used for simulation in Abaqus FEM. The model is built up using both 3-node linear displacement and temperature and 4-node bilinear displacement and temperature, reduced integration with hourglass control elements (CPE3T, CPE4RT in Abaqus notation). The FE model is constructed in such way that the most elements have a rectangular shape and retain this shape during mesh sensitivity analysis, changing only the dimensions of elements. The mesh near the free edge zone (the zone of cut) is more detailed in order to see the emerging effects in this area. The FE model with Local (123) and Global (XYZ) coordinate system is shown in Figure 4.

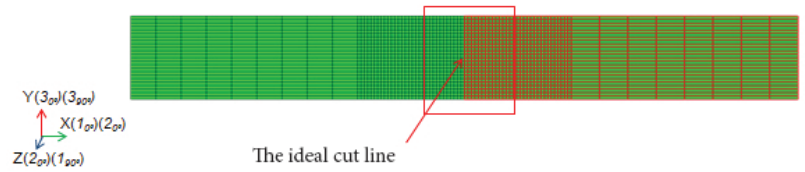

Figure 4. FE model for the sample $3.12 \mathrm{~mm}$ thick, orientation $\left[0^{\circ} / 90^{\circ}\right]_{\mathrm{S}}$ and 8 elements per 1 composite layer in the free edge zone

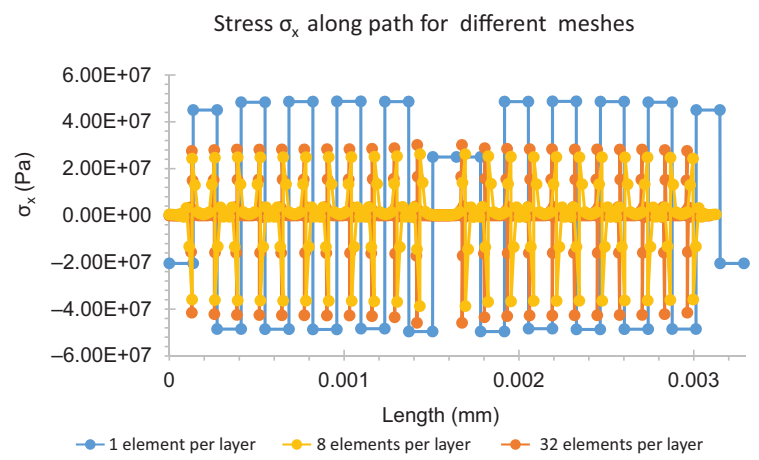

Matching of stress components in local and global coordinate systems for different layers is shown in Table 1.

Table 1. Matching of stress components in local and global coordinate systems

\begin{tabular}{|c|c|c|}
\hline Global CSYS & $\begin{array}{c}\text { Local CSYS for layers } \\
\text { with } 0^{\circ} \text { orientation }\end{array}$ & $\begin{array}{c}\text { Local CSYS for layers } \\
\text { with } 90^{\circ} \text { orientation }\end{array}$ \\
\hline$\sigma_{\mathrm{x}}$ & $\sigma_{22}$ & $\sigma_{11}$ \\
\hline$\sigma_{\mathrm{y}}$ & $\sigma_{33}$ & $\sigma_{33}$ \\
\hline$\sigma_{\mathrm{z}}$ & $\sigma_{11}$ & $\sigma_{22}$ \\
\hline$\sigma_{\mathrm{xy}}$ & $\sigma_{23}$ & $\sigma_{13}$ \\
\hline
\end{tabular}

To correctly calculate strain matrix of composite (it was done in UMAT), two types of materials were usedMaterial-1 ( $0^{\circ}$ layers) and Material-2 ( $90^{\circ}$ layers). The thermo-mechanical properties of each ply were calculated in Umat during each increment.

\section{Results of simulation}

As the FE analysis is mesh dependent it is required to provide a mesh refinement study. Such analysis was provided by tabulating the result a specific location versus the characteristic element size for solutions from different meshes - 1, 2, 4, 8, 16, 32 elements per composite layer in the free edge zone. In Figure 5 it is shown the difference in results of the simulation $\left(\sigma_{\mathrm{x}}, \sigma_{\mathrm{y}}\right.$ along path- 1 in global coordinate system) for different meshes between the values obtained on the "finest" mesh (32 elements per layer) on the last step of the analysis.

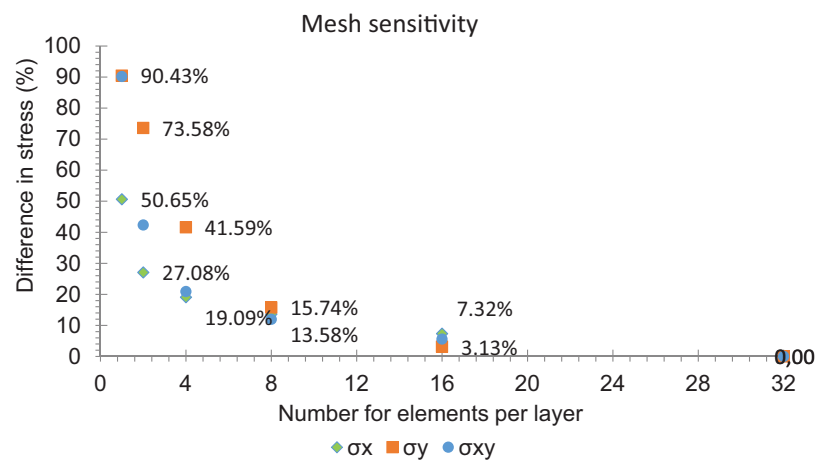

Figure 5. Mesh size sensitivity analysis 

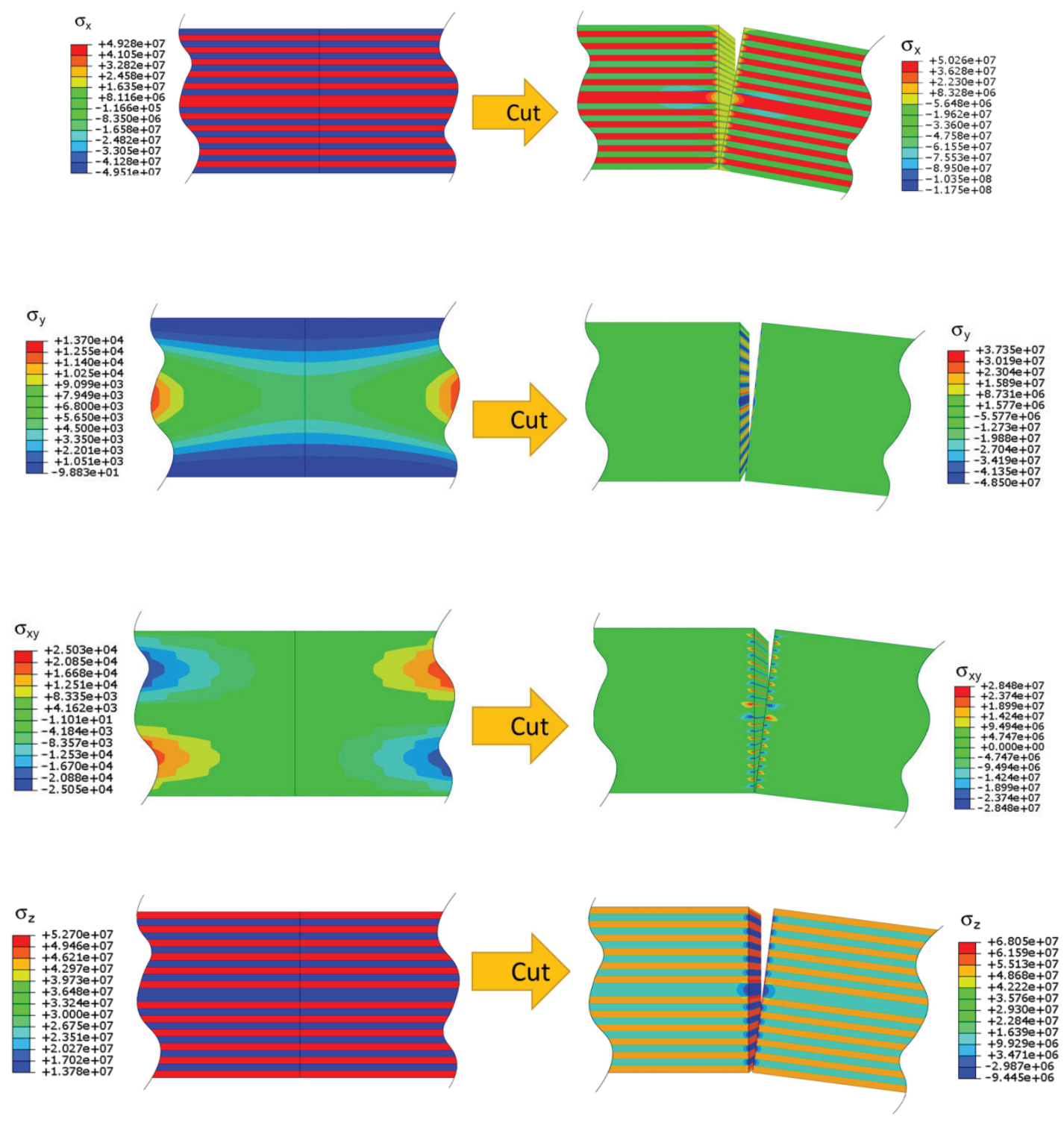

Figure 6. Stress distribution in sample after polymerization and before cut

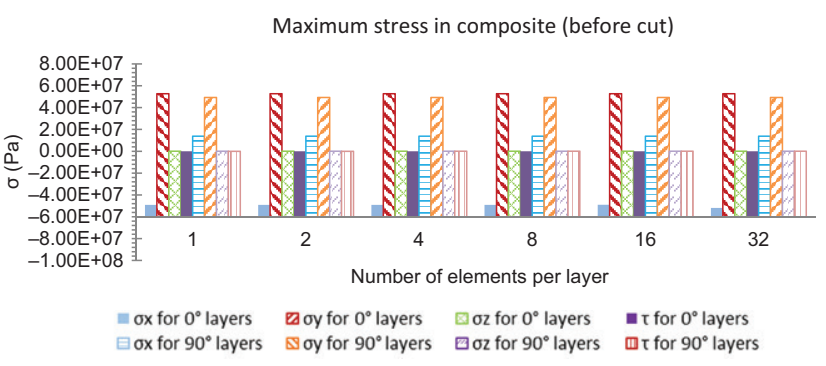

Figure 7. Maximum stress through the sample thickness in composite before a cut

The results of FE simulation for the polymerized sample before cut and after cut out is provided in Figure 6. Stress distribution is provided for finite mesh with 32 elements per composite layer in the free edge zone. Stress distribution with a pronounced local change in stress in the cut-off zone can be seen in the free edge region.

Overall it is clear that longitudinal stress $\left(\sigma_{11}\right.$ in local CSYS and $\sigma_{\mathrm{x}}$ in global CSYS) varies significantly depending on the size of the element compared to other stresses (Figures 5-7). Due to the fact that the value of longitudinal stress (in Global CSYS) doesn't change only since 4 elements per layer, there is a possibility to have a mistake providing 2D analysis.

Let us remark that, the $\sigma_{\mathrm{y}}$ stress before cut and after cut change insignificantly (see Figure 8(b)). At the same time, the tremendous increase in $\sigma_{\mathrm{z}}$ and especially $\tau_{\mathrm{xz}}$ maximum stresses through the thickness after cut can be observed in Figure 8(c, d).

The result of simulation - stress distribution, is provided on Figure 9. 
(a)

$$
\text { Max } \sigma_{\mathrm{x}} \text { before cut/Max } \sigma_{\mathrm{x}} \text { (through }
$$
the thickness) after cut

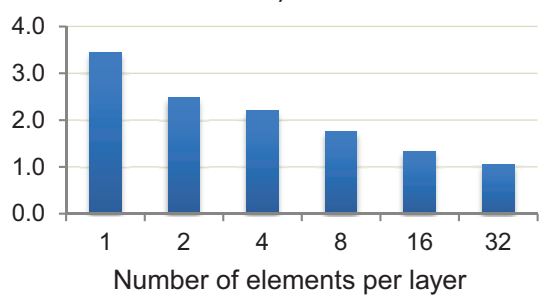

Max $\sigma_{z}$ before cut/Max $\sigma_{z}$ (through the thickness) after cut

(c)

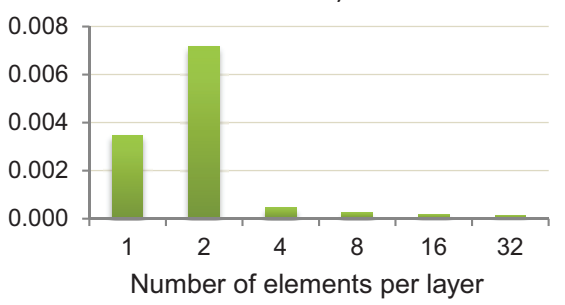

(b)

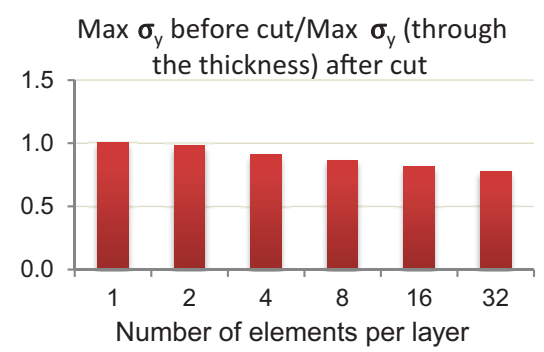

(d)

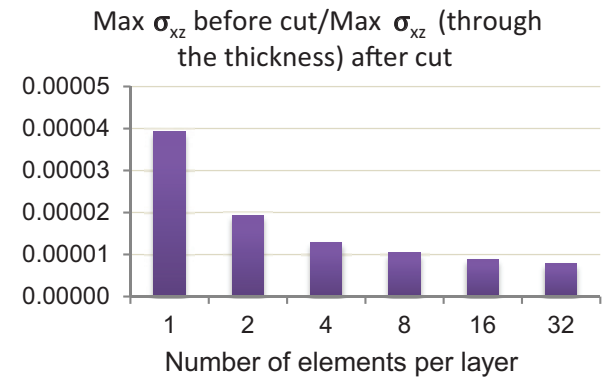

Figure 8 . The ratio of maximum stress through the thickness in composite for both $0^{\circ}$ layers and $90^{\circ}$ layers (in Global CSYS) before cut to stress after cut

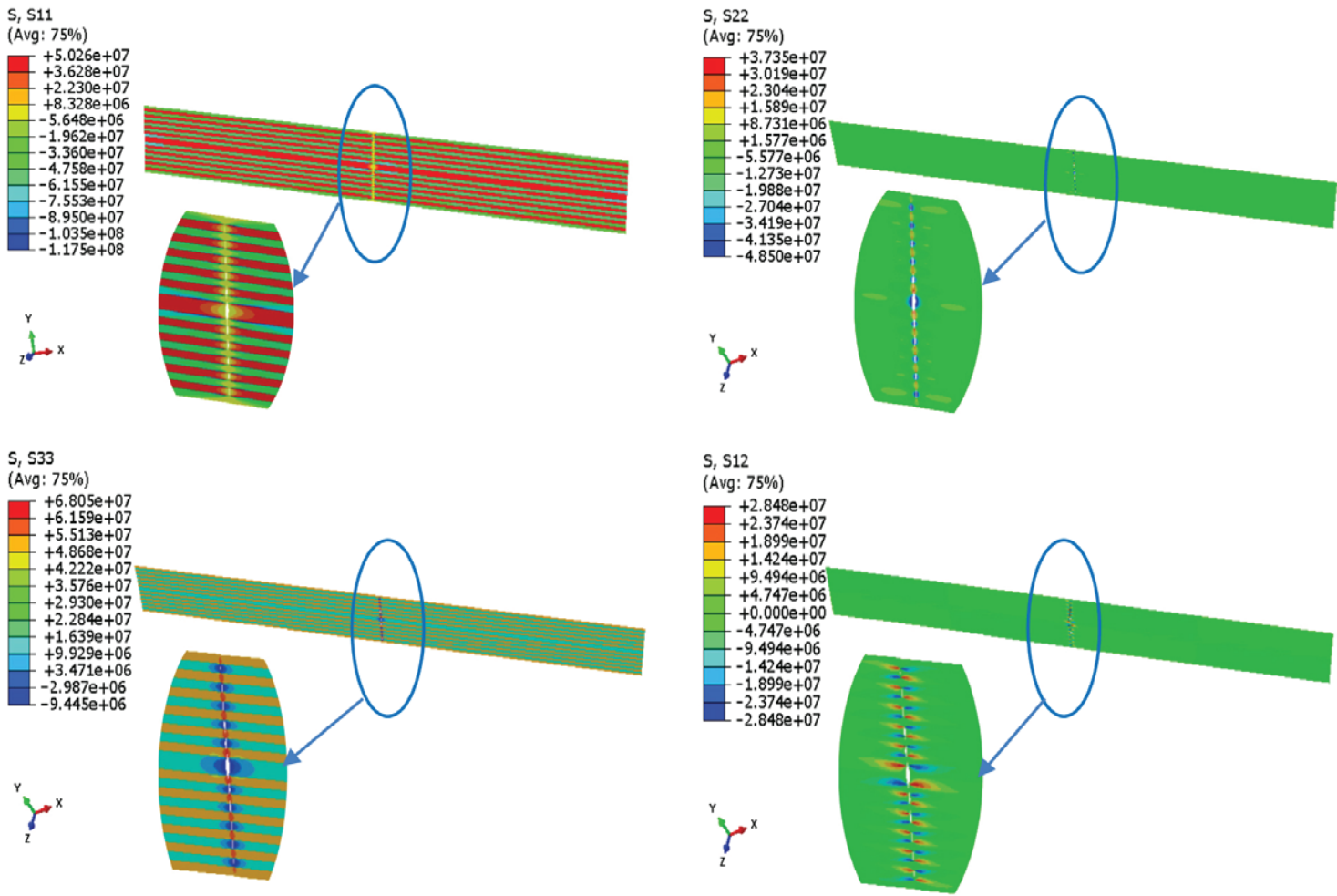

Figure 9. Stress distribution in the sample after cut (Global CSYS) 


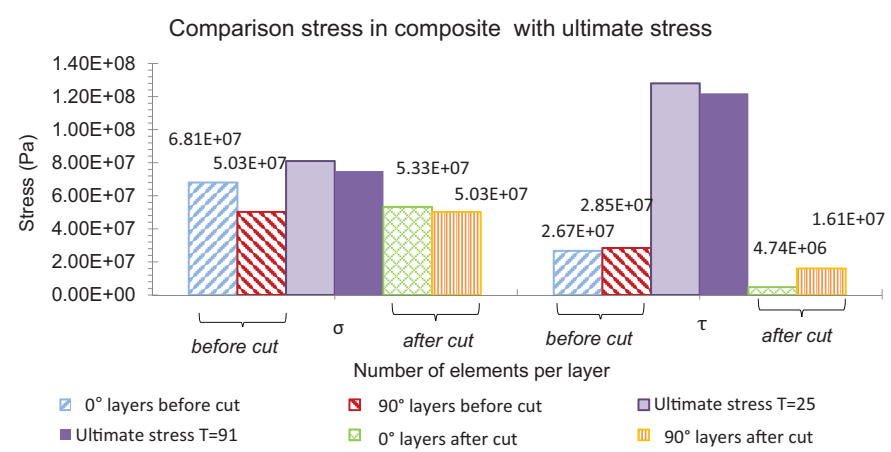

Figure 10. Comparison stress in composite after the cut with the ultimate stress

The bar chart diagram (Figure 10) shows that maximum stress in the transverse direction $\left(\sigma_{y}\right)$, mainly concentrated in a quite small area, and is close to the ultimate stress of composite material provided in datasheet (Hexply 8552,2019$)$. Thus there is a possibility of formation of microcracks in sample during manufacturing or at low load, which confirms the conjecture about the reduction of mechanical performance, especially for matrix-dominated properties by residual stresses. The results of the simulation are consistent with the conclusions indicated in the article (Zobeiry et al., 2016).

\section{Conclusions}

In current research, an extensive investigation of stress concentration phenomena near free edge of AS4/8552-1 carbon-epoxy multilayered composite was provided by means of FE analysis. The problem was solved for the particular case - for the composite sample with $\left[0^{\circ} / 90^{\circ}\right]_{12}$ lay-up and ideal cut into two parts after curing. The behavior of material during manufacturing and distribution of locked-in stresses was studied with help of a developed program that was implemented in Abaqus software. Based on simulation results it can be concluded that maximum stresses (after cut) in the sample are close to the ultimate and concentrated in a small area near free edge.

According to data provided in the product data sheet for HexPly 8552, $90^{\circ}$ tensile strength for prepreg AS4/8552 - is $81 \mathrm{MPa}$. The maximum stress for samples after polymerization before cut is $52.7 \mathrm{MPa}$ and for samples with concentrator even higher - $68 \mathrm{MPa}$. Thus, the values for stresses are essential and cannot be ignored in consequent stress analysis.

It is worth noting that the data provided for particular composite material by manufacturer contains data for UD composite or for samples with stacking of prepreg layers in one direction which in fact are not entirely valid for composites with complex laying since they do not take into account the effects described before.

The results of analysis vary significantly depending on the size of an element. There is a possibility to have a mistake providing $2 \mathrm{D}$ analysis. It should be also noted, that the described effects on the free edge of a composite can be observed using continuum (solid) elements.

The developed model (of polymerization) can be used for prediction of failure in composite without the need for a large number of tests. As a future work, the problem can be solved in general case for composite with arbitrary lay-up.

\section{References}

Amrutharaj, G. S., Lam, K. Y., \& Cotterell, B. (1996). Delaminations at the free edge of a composite laminate. Composites Part B: Engineering, 27(5), 475-483.

https://doi.org/10.1016/1359-8368(96)00015-7

Baran, I., Cinar, K., Ersoy, N., Akkerman, R., \& Hattel, J. H. (2017). A review on the mechanical modeling of composite manufacturing processes. Archives of Computational Methods in Engineering, 24(2), 365-395.

https://doi.org/10.1007/s11831-016-9167-2

Chachad, Y. R., Roux, J. A., Vaughan, J. G., \& Arafat, E. (1995). Three-dimensional characterization of pultruded fiberglassepoxy composite materials. Journal Reinforced Plastics and Composites, 14, 495-512.

https://doi.org/10.1177/073168449501400506

Fedulov, B. N., Safonov, A. A., Kantor, M. M., \& Lomov, S. V. (2017). Modelling of thermoplastic polymer failure in fiber reinforced composites. Composite Structures, 163, 293-301. https://doi.org/10.1016/j.compstruct.2016.11.091

Fedulov, B. N., Safonov, A. A., Sergeichev, I. V., Ushakov, A. E., Klenin, Y. G., \& Makarenko, I. V. (2016). Strength analysis and process simulation of subway contact rail support bracket of composite materials. Applied Composite Materials, 23(5), 999-1013. https://doi.org/10.1007/s10443-016-9495-2

Hajikazemi, M., \& Van Paepegem, W. (2018). A variational model for free-edge interlaminar stress analysis in general symmetric and thin-ply composite laminates. Composite Structures, 184, 443-451. https://doi.org/10.1016/j.compstruct.2017.10.012

Hexply 8552. (2019). Epoxy matrix product datasheet. Retrieved from https://www.hexcel.com/user_area/content_media/raw/ HexPly_8552_eu_DataSheet.pdf

Hu, S., Karpur, P., Matikas, T. E., Shaw, L., \& Pagano, N. J. (1995). Free edge effect on residual stresses and debond of a composite fibre/matrix interface. Mechanics of Advanced Materials and Structures, 2(3), 215-225.

Islam, M. S., \& Prabhakar, P. (2017). Modeling framework for free edge effects in laminates under thermo-mechanical loading. Composites Part B: Engineering, 116, 89-98. https://doi.org/10.1016/j.compositesb.2017.01.072

Johnston, A. A. (1997). An integrated model of the development of process-induced deformation in autoclave processing of composite structures ( $\mathrm{PhD}$ thesis). The University of British Columbia, Canada. Retrieved from https://open.library.ubc.ca/ cIRcle/collections/ubctheses/831/items/1.0088805

Johnston, A., Vaziri, R., \& Poursartip, A. (2001). A plane strain model for process-induced deformation of laminated composite structures. Journal of Composite Materials, 35(16), 1435-1469. https://doi.org/10.1106/YXEA-5MH9-76J5-BACK

Khoun, L., Centea, T., \& Hubert, P. (2010). Characterization methodology of thermoset resins for the processing of composite materials - case study: CYCOM 890RTM epoxy resin. Journal of Composites Materials, 44, 1397-1415. https://doi.org/10.1177/0021998309353960 
Li, D., Li, X., Dai, J., \& Xi, S. (2017). A comparison of curing process-induced residual stresses and cure shrinkage in micro-scale composite structures with different constitutive laws. Applied Composite Materials, 25(5), 1-18.

Mittelstedt, C., \& Becker, W. (2007). Free-edge effects in composite laminates. Applied Mechanics Reviews, 60(5), 217-245. https://doi.org/10.1115/1.2777169

Rasuo, B., \& Dinulovic, M. (2011). Free-edge stresses in composite laminates under mechanical loading. Paper presented at the 18 th International Conferences on Composite Materials. Retrieved from https://www.researchgate.net/publication/287678229_Free-edge_stresses_in_composite_laminates_under_mechanical_loading

Solis, A., Sánchez-Sáez, S., \& Barbero, E. (2018). Influence of ply orientation on free-edge effects in laminates subjected to in-plane loads. Composites Part B: Engineering, 153, 149-158. https://doi.org/10.1016/j.compositesb.2018.07.030
Ushakov, A. E., Safonov, A. A., Sergeichev, I. V., Fedulov, B. N., Kornienko, E. I., Timofeev, M. A., Izotov, A. V., Klenin, Yu. G., \& Rozin, N. V. (2015). Design and optimization of a vacuum infusion technological process for hopper car fabrication using polymeric composite materials. Journal of Machinery Manufacture and Reliability, 44(3), 276-282. https://doi.org/10.3103/S105261881503022X

Wijskamp, S., Akkerman, R., \& Lamers, E. A. D. (2003). Residual stresses in non-symmetrical carbon-epoxy laminates. In M. J. Martin \& H. T. Hahn (Eds.), Proceedings of the 14th International conference on Composite Materials, ICCM14 (pp. 1-10). San Diego, USA.

Zobeiry, N., Forghani, A., Li, C., Gordnian, K., Thorpe, R., Vaziri, R., Fernlund, G., \& Poursartip, A. (2016). Multiscale characterization and representation of composite materials during processing. Philosophical Transactions of the Royal Society A: Mathematical, Physical and Engineering Sciences, 374, 1-20. https://doi.org/10.1098/rsta.2015.0278 